\title{
Electrical Resistivity Structure of the Snail Site at the Southern Mariana Trough Spreading Center
}

\author{
Tetsuo Matsuno, Maho Kimura, and Nobukazu Seama
}

\begin{abstract}
The electrical resistivity of the oceanic crust is sensitive to the porosity of the crust and the fluid temperature within crustal fractures and pores. The spatial variation of the crustal porosity and the fluid temperature that is related to a hydrothermal circulation can be deduced by revealing an electrical resistivity structure of the oceanic crust involving a hydrothermal site. We carried out a magnetometric resistivity experiment using an active source to reveal an electrical resistivity structure of the oceanic crust at the Snail site on the ridge crest of the Southern Mariana Trough. Active source electric currents were transmitted along and across the ridge axis in a $4,000 \mathrm{~m}^{2}$ area including the Snail site. Five ocean bottom magnetometers were deployed around the Snail site as receivers to measure the magnetic field induced by the transmission of the active source electric currents. The amplitude of the induced magnetic field was calculated by maximizing data density and the signal to error ratio in the data, and locations of the transmissions were determined using several types of calibration data. An optimal 1-D resistivity structure of the oceanic crust, averaged over the experimental area, was deduced by least squares from the data of the amplitude of the magnetic field and the location of the transmission. After calculating magnetic field anomalies, which are deviations of the observed amplitude from the prediction of the optimal 1-D resistivity model, an optimal 3-D resistivity structure was deduced from the magnetic field anomalies through trial and error 3-D forward modeling. The optimal 1-D resistivity structure is a two-layer model, which consists of a $5.6 \Omega-\mathrm{m}$ upper layer having a $1,500 \mathrm{~m}$ thickness and a $0.1 \Omega-\mathrm{m}$ underlying half-space. Using Archie's law and porosity profiles of the oceanic crust, the resistivity of $5.6 \Omega-\mathrm{m}$ at depths ranging from 800 to $1,500 \mathrm{~m}$ suggests the presence of hightemperature fluid related to the hydrothermal circulation. The resistivity of $0.1 \Omega-\mathrm{m}$ below $1,500 \mathrm{~m}$ depth may represent a magma mush that is a heat source for the hydrothermal circulation. The optimal 3-D resistivity structure includes a conductive anomaly $(0.56 \Omega-\mathrm{m}$ in approximately $300 \mathrm{~m}^{2}$ area down to $400 \mathrm{~m}$ depth) immediately below the Snail site, two resistive anomalies ( $56 \Omega$-m with slightly larger volumes than the conductive anomaly) adjacent to the conductive anomaly on the across-ridge side, and three conductive anomalies away from the Snail site. The conductive anomaly immediately below the Snail site suggests hydrothermal fluid, and the adjacent resistive anomalies suggest areas of low porosity. The size and distribution of the conductive and resistive anomalies near the Snail site constrains the size and style of the hydrothermal circulation.
\end{abstract}

T. Matsuno $(\bowtie)$

National Institute of Polar Research, 10-3 Midoricho, Tachikawa,

Tokyo 190-8518, Japan

Earthquake Research Institute, University of Tokyo,

1-1-1 Yayoi, Bunkyo, Tokyo 113-0032, Japan

M. Kimura $\bullet$ N. Seama

Department of Earth and Planetary Sciences, Kobe University,

e-mail: tmatsuno@eri.u-tokyo.ac.jp 1-1 Rokkodai, Nada, Kobe 657-8501, Japan 
Keywords

Electrical resistivity structure - Hydrothermal circulation - Magnetometric resistivity method $\bullet$ Oceanic crust $\cdot$ Temperature and porosity

\subsection{Introduction}

The Mariana Trough has been an active back-arc basin since its rifting and subsequent seafloor spreading approximately 6 Ma ago (e.g., Hussong and Uyeda 1982; Fryer 1996). The southern part of the Mariana Trough is inferred to be in an area of high melt production (e.g., Martínez et al. 2000; Kitada et al. 2006). A group of hydrothermal sites, which are called as the Snail, Yamanaka, Archaean, Pika, and Urashima sites, have been discovered on and off the ridge axis of the Southern Mariana Trough at $12^{\circ} 55^{\prime}$ to $12^{\circ} 57^{\prime} \mathrm{N}$ (e.g., YK03-09 and YK05-09 cruise reports; Urabe et al. 2004; Kakegawa et al. 2008). The heat source for hot fluid venting at the hydrothermal sites is expected to come from abundant magma sources. A thicker seismic layer 2 (upper crust) with a lower seismic velocity than other normal mid-ocean ridges in a $15 \mathrm{~km}^{2}$ area at $12^{\circ} 56^{\prime} \mathrm{N}$ suggests an abundant melt production under the hydrothermal sites, which is affected by the high content of volatiles derived from the subducted Pacific slab (Sato et al. Chap. 18). A low velocity structure under the on-ridge sites (Snail and Yamanaka) suggests that a heat source is present for hydrothermal circulations at these sites, and a high velocity structure under the off-ridge sites (Archaean, Pika, and Urashima) suggests a thick seismic layer 3 (lower crust) and a residual heat source for hydrothermal circulations (Sato et al. Chap. 18). Low seismicity under the on and off ridge sites indicates that tectonic stresses resulting in faulting are not related to the hydrothermal activity (Sato et al. Chap. 18). In addition to the group of hydrothermal sites, a seismic reflector was observed approximately $15 \mathrm{~km}$ northeast along the spreading axis at approximately $3 \mathrm{~km}$ depth at $13^{\circ} 05^{\prime} \mathrm{N}$, indicating the presence of a magma chamber (Becker et al. 2010).

The Snail site, which is the target of this study, is located at a mound cut by fissures on the ridge crest and is surrounded by unaltered pillow lavas and sheet dykes (Urabe et al. 2004; Yoshikawa et al. 2012; Kakegawa et al. 2008). A diking event is possibly related to development of the site, and hence, the life span of the hydrothermal circulation is inferred to be relatively short (Yoshikawa et al. 2012). Hot fluid at approximately $250{ }^{\circ} \mathrm{C}$ was venting at the time of its discovery in May 2003. The temperature of the fluid decreased to $\leq 116^{\circ} \mathrm{C}$ in October 2003 and to $110{ }^{\circ} \mathrm{C}$ in July 2005 (Wheat et al. 2003; Kakegawa et al. 2008; YK05-09 cruise report). The low temperature of the vent fluid was a result of sub-seafloor mixing of cold seawater and hot fluid $\left(>300{ }^{\circ} \mathrm{C}\right)$ (Ishibashi et al. 2006). Thin sulfide layers having a $3-15 \mathrm{~cm}$ thickness covers altered pillow lavas around the northeastern discharging zone, and low temperature fluid at $20-40{ }^{\circ} \mathrm{C}$ vents from clay mounds in the southwestern area (Kakegawa et al. 2008). These observations suggest that hydrothermal circulation under the Snail site occurs on a several or more tens of meters scale and that spatial variation in the porosity and permeability, which controls the size and geometry of the hydrothermal circulation, exists on a similar scale.

The electrical resistivity of the oceanic crust changes with the porosity of the crust, the amount and connectivity of fluid within the crust, and the temperature of the crust and the fluid. This property of the electrical resistivity suggests that a spatial variation in the porosity and the temperature of fluid within the crust is deduced by revealing an electrical resistivity structure of the oceanic crust. The magnetometric resistivity (MMR) technique is useful for revealing the electrical resistivity structure of the oceanic crust (e.g., Edwards et al. 1981). The first application of the MMR technique for exploring an electrical resistivity structure of an active hydrothermal system was implemented off the Juan de Fuca Ridge by Nobes et al. (1986), Nobes et al. (1992). Evans et al. (1998) conducted a MMR experiment at the Juan de Fuca Ridge. They determined electrical resistivity structures down to $1 \mathrm{~km}$ depth below the seafloor on and off the ridge axis, and concluded that a low resistivity structure found on the ridge axis at 600-800 $\mathrm{m}$ depth was related to a recent dike intrusion event and subsequent high-temperature fluid circulation. A MMR experiment at the East Pacific Rise also revealed a low resistivity structure on the ridge axis, suggesting the presence of hot pore-fluids beneath the ridge center (Evans et al. 2002). Tada et al. (2005) conducted a MMR experiment at the Alice Spring Field site on the backarc spreading ridge in the central Mariana Trough, and discussed the temperature of hydrothermal fluid and the spatial variation of the hydrothermal circulation based on 1-D electrical resistivity profiles on and off ridge axes.

We present a result of a MMR experiment conducted at the Snail site in the Southern Mariana Trough in this contribution. A summary of the MMR experiment and magnetic field data obtained in the experiment is described first. The magnetic field data are analyzed to obtain a 1-D electrical resistivity structure averaged over the experimental area and then to obtain a detailed 3-D electrical resistivity 
structure of the experimental area. The resulting 1-D and 3-D electrical resistivity structures are presented, and their features are discussed in terms of the hydrothermal system at the Snail site.

\subsection{MMR Experiment}

The MMR experiment was conducted at the Snail site from November 21 to 30 in 2003 during the KR03-13 cruise of $R / V$ Kairei from the Japan Agency for Marine-Earth Science and Technology (JAMSTEC). Instruments used in the MMR experiment are categorized into transmitter, receiver, and calibrator. The transmitter comprised two electrodes connected by an insulated wire, one of which was set near the sea surface (upper electrode), and the other of which was set near the seafloor (lower electrode). The electrodes were strung out from the stern of the ship. The upper electrode was kept at $7 \mathrm{~m}$ below the sea surface and the lower electrode was kept at $20 \mathrm{~m}$ above the seafloor. A rectangular alternating current at a period of $16 \mathrm{~s}$, with a peak current of $16 \mathrm{~A}$, was applied between the electrodes for the active source electric current. The receiver comprised five ocean bottom magnetometers (OBMs). The OBMs, which each houses a fluxgate magnetometer, measured the time variation of the three-component magnetic field at a sampling rate of $1 \mathrm{~s}$. The observed magnetic field includes the component induced in the crust by applying the electric current through the transmitter. A two-component tilt meter was equipped on the OBM to measure the instrumental tilt and to correct the tilt for the data analysis. The calibrator comprised a GPS, acoustic transponder, and Super Short Base Line (SSBL) system. The GPS system mounted on the ship was used to determine the location of the ship. The acoustic transponder was attached $100 \mathrm{~m}$ above the lower electrode along the insulated wire to measure its own seawater depth and height above the seafloor, as well as the distances between the acoustic transponder, the ship, and the OBM. The SSBL system equipped on the ship bottom was used to locate the lower electrode and the acoustic transponder.

The active source electric current was applied during ship runs along five transmission lines (L1-5) and at ten stationary points on the ends of the lines (Fig. 19.1). The location of the upper electrode was determined from the GPS position of

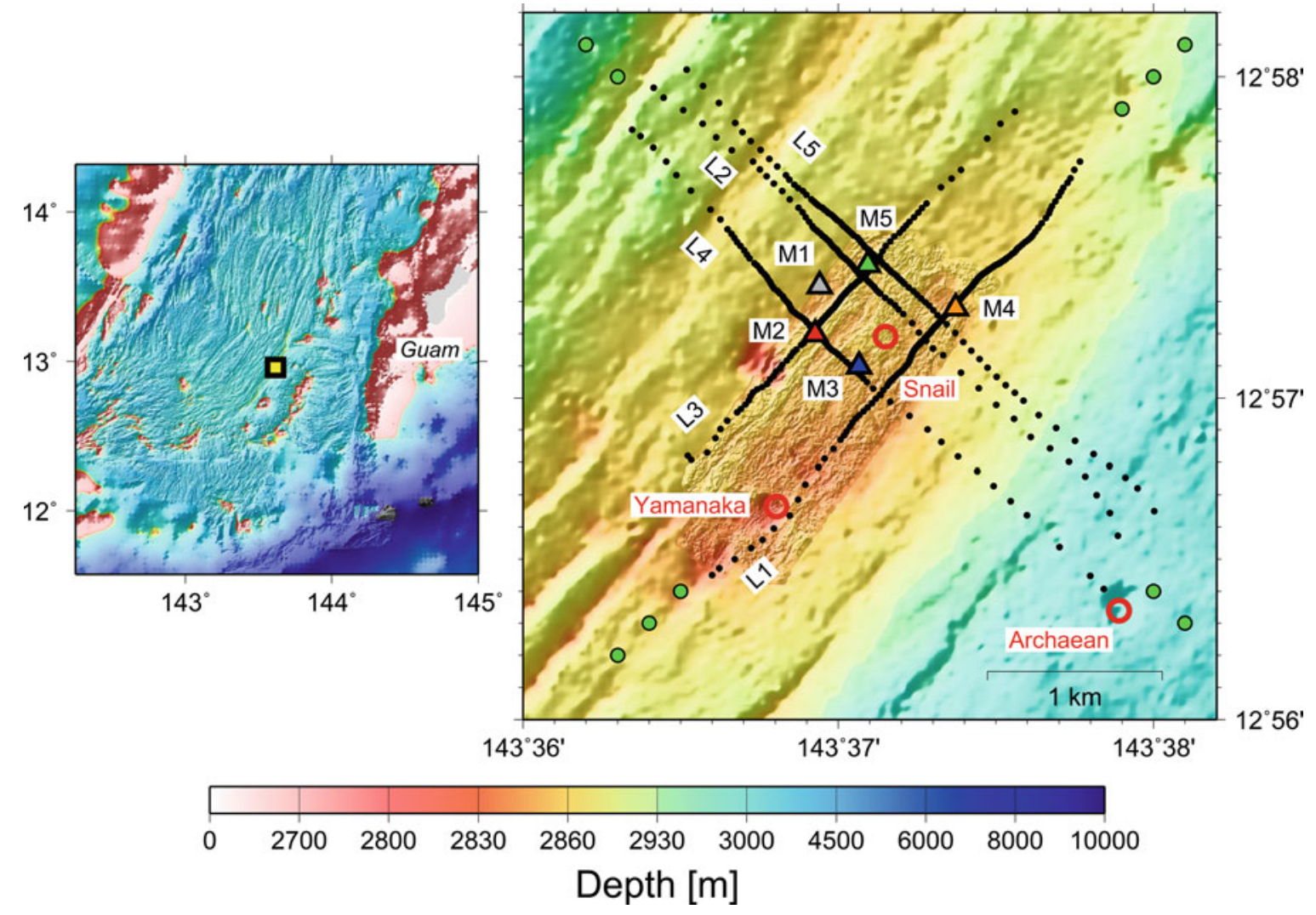

Fig. 19.1 An area map including the MMR experimental area (left), and a detailed MMR experimental area map (right). The yellow square in the left map indicates the location of the experimental area. Symbols in the right map denote the followings: colored triangles with names, locations of receivers (M); filled circles, transmission points during the ship runs along lines; light green circles on ends of transmission lines, stationary transmission points; red circles with names, locations of known hydrothermal sites. Names for the transmission lines (L) are also shown. High-resolution seafloor topography data on the ridge crest in the right figure are given from Yoshikawa et al. (2012) 
Table 19.1 Location and depth of the receiver OBMs determined through a grid search, and RMS misfit distance in the determination of the OBMs' positions

\begin{tabular}{lllll}
\hline Receiver & Latitude & Longitude & Depth (m) & $\begin{array}{l}\text { RMS misfit } \\
\text { distance (m) }\end{array}$ \\
\hline M1 & $12^{\circ} 57.348^{\prime} \mathrm{N}$ & $143^{\circ} 36.942^{\prime} \mathrm{E}$ & 2,858 & 1 \\
\hline M2 & $12^{\circ} 57.199^{\prime} \mathrm{N}$ & $143^{\circ} 36.927^{\prime} \mathrm{E}$ & 2,862 & 4 \\
M3 & $12^{\circ} 57.098^{\prime} \mathrm{N}$ & $143^{\circ} 37.066^{\prime} \mathrm{E}$ & 2,845 & 4 \\
\hline M4 & $12^{\circ} 57.280^{\prime} \mathrm{N}$ & $143^{\circ} 37.373^{\prime} \mathrm{E}$ & 2,855 & 8 \\
\hline M5 & $12^{\circ} 57.415^{\prime} \mathrm{N}$ & $143^{\circ} 37.094^{\prime} \mathrm{E}$ & 2,858 & 2 \\
\hline
\end{tabular}

the ship and a visual measurement of the distance to the electrode from the stern. The location of the lower electrodes was determined by using several types of calibration data of the GPS, the acoustic transponder, the OBM, and the SSBL system. The ship speed was kept at 0.5 knots during the transmission along the lines to minimize a horizontal displacement between the upper and lower electrodes as well as the operation time for the experiment. The horizontal displacement between the upper and lower electrodes, which is not avoided as far as the ship runs, may be a problem in the MMR data analysis because the bipole for the source current is assumed to be vertical in the MMR technique theory (e.g., Edwards et al. 1981). The location of the transmission point along the lines is approximated by the horizontal midpoint between the upper and lower electrodes. The validity of this approximation was demonstrated by Seama et al. (2013). The location of the transmission at the stationary points is supposed to be consistent with that of the upper electrode because the ship did not run. The electric current was applied for $30 \mathrm{~min}$ at the stationary transmission points.

The five OBMs were deployed on the seafloor as surrounding the Snail site with separations of $300-800 \mathrm{~m}$ (Fig. 19.1). The locations of the OBMs were determined by minimizing misfits in slant range between the observation and the prediction through a grid search (Table 19.1). Out of the five OBMs, four OBMs (M2-5) measured the magnetic field during the L1 line transmissions, and the remaining OBM (M1) measured the magnetic field during the L2-5 line transmissions.

\subsection{Data Analysis}

\subsubsection{Processing the Magnetic Field Data}

Data measured by the receiver OBM is a three-component magnetic field in the time domain with the instrumental tilt. The instrumental tilt was corrected to retrieve a threecomponent magnetic field without the influence of the instrumental tilt, and then, a net force of the horizontal two components was obtained. The horizontal net force magnetic field was next processed through the fast Fourier transformation to obtain the amplitude of the magnetic field at a period of $16 \mathrm{~s}$, which is the same period as that of the transmitter electric current. The amplitude of the magnetic field was finally normalized by the peak ampere of the electric current, $16 \mathrm{~A}$.

Six length data segments in the time-domain $(32,64,128$, 256,512 , and $1,024 \mathrm{~s}$ ) were used to calculate the amplitude of the magnetic field at $16 \mathrm{~s}$. The longer length segment was used for the longer transmitter-receiver separation, and the shorter length segment was used for the shorter separation. Using variable length segments, which has not been done in previous MMR studies, is useful not only to obtain a higher density of amplitudes at the shorter separation but also to ensure a good signal to noise ratio of the amplitude at the longer separation (one datum of the amplitude per approximately $10 \mathrm{~m}$ separation with a $10^{-10.7} \mathrm{~T} / \mathrm{A}$ noise level for the 32 s segment, and one datum of the amplitude per approximately $100 \mathrm{~m}$ separation with a $10^{-11.5} \mathrm{~T} / \mathrm{A}$ noise level for the 1,024 s segment) (Fig. 19.2). Segments were overlapped by their half length to augment the number of data stacking to obtain a good signal to noise ratio of the amplitude (for example, $32 \mathrm{~s}$ segments were overlapped by $16 \mathrm{~s}$ ). The noise level in the magnetic field amplitude was determined by averaging two adjacent non-transmission data to the $16 \mathrm{~s}$ transmission data in the frequency domain.

\subsubsection{Obtaining a One-Dimensional Electrical Resistivity Structure}

A 1-D electrical resistivity structure under the experimental area was obtained by using the data of the amplitude of the magnetic field and the horizontal separation between the transmitter and the receiver. All data pairs of the transmitter and the receiver were used, meaning that the resulting 1-D resistivity structure should represent a structure averaged over an area covered by all of the pairs of the transmitter and the receiver. An optimal 1-D electrical resistivity structure was determined by a least squares fitting of the model prediction to the observation. The model prediction was obtained from the analytical solution of Edwards et al. (1981).

\subsubsection{Obtaining a Three-Dimensional Electrical Resistivity Structure}

A 3-D electrical resistivity structure was examined by trial and error forward modeling of magnetic field anomaly for all of the transmission points. The magnetic field anomaly is obtained by subtracting the magnetic field amplitude predicted from the optimal 1-D resistivity structure model $\mathbf{B}_{p}$ from that observed $\mathbf{B}_{o}$ in logarithmic scale $\left(\log \left|\mathbf{B}_{o}\right|-\right.$ $\left.\log \left|\mathbf{B}_{p}\right|\right)$. A program developed by Tada et al. (2011) was 


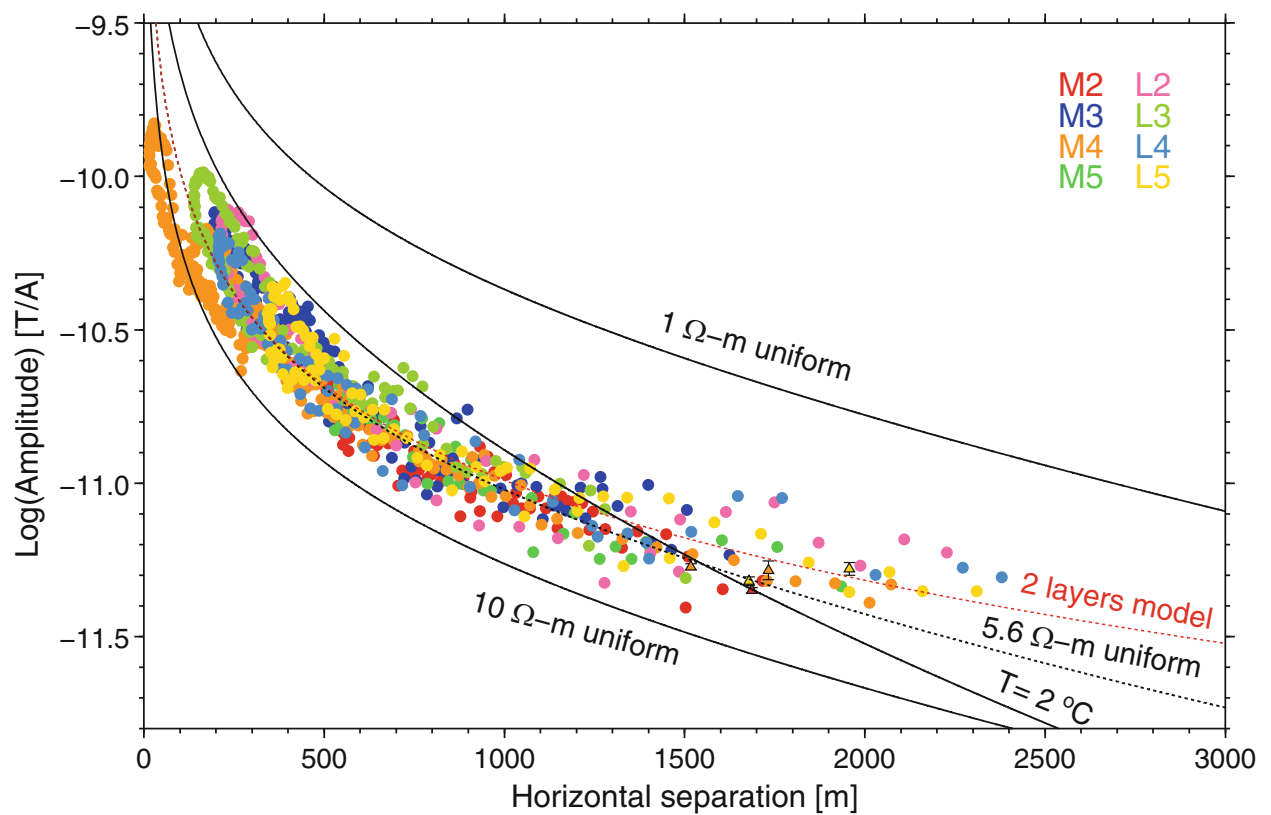

Fig. 19.2 The amplitude of the magnetic field for the horizontal separation between the transmitter and the receiver. Observed amplitudes are represented by colored circles and model predictions are shown by solid and dotted lines. The names of the receivers and the transmission lines are shown at the upper right in the figure. Circles with " $\mathrm{M}$ " denote each receiver data for the L1 line transmissions, and those with "L" denote data of the M1 receiver for each transmission line. Data at stationary transmission points are shown by colored triangles with error bars (one standard deviation) at 1,500-2,000 m horizontal separation. Solid lines with " $1 \Omega$-m uniform" and "10 $\Omega-\mathrm{m}$ uniform" represent analytical solutions of Edwards et al. (1981) for each uniform resistivity structure. A black dotted line represents an analytical solution for the $5.6 \Omega-\mathrm{m}$ uniform structure that is best fitted to the observations, and a red dotted line represents an analytical solution for a best fitting two-layer resistivity structure. The best fitting two-layer model comprises an upper layer with $5.6 \Omega$-m and a $1,500 \mathrm{~m}$ thickness and an underlying $0.1 \Omega$-m half-space. A black solid line with "T $=2{ }^{\circ} \mathrm{C}$ " is an analytical solution assuming $2{ }^{\circ} \mathrm{C}$ seawater at depths of $800-1,500 \mathrm{~m}$ for the bulk resistivity of $5.6 \Omega-\mathrm{m}$, the exponent in Archie's law of 1.2, and a porosity profile from Evans et al. (1998) (Fig. 19.8a); see the discussion section in text

\subsection{Result}

\subsubsection{One-Dimensional Electrical Resistivity Structure}

The seafloor depth is a constant $2,900 \mathrm{~m}$, and the subseafloor modeling area has a thickness of $1,100 \mathrm{~m}$. The depth of the lower electrode is $2,850 \mathrm{~m}$. The electric current intensity of the active source is $1 \mathrm{~A}$ for modeling the magnetic field amplitude normalized by the applied electric current. The resistivity of seawater is $0.3 \Omega-\mathrm{m}$, and that of the crust is $5.6 \Omega-\mathrm{m}$, which is for the optimal 1-D resistivity structure and is described later in detail. Three-dimensional resistivity anomalies examined are cuboid with lower and higher resistivity values than $5.6 \Omega$-m by one order of magnitude in logarithmic scale (i.e., 0.56 and $56 \Omega$-m). The actual transmission lines were not strictly straight due to the movement and drift of the ship and the electrodes, but deviations from the straight lines are small as they are almost less than a few tens of meters (Fig. 19.1). Hence, transmission lines are set to be linear in the forward modeling.
The amplitude of the magnetic field at $16 \mathrm{~s}$ with the horizontal separation between the transmitter and the receiver is plotted in Fig. 19.2. The amplitudes decay with a larger horizontal separation and are within the predictions of uniform 1-D resistivity models with 1 and $10 \Omega-\mathrm{m}$. The resistivity of the uniform resistivity structure fitted to all of the data was determined to be $5.6 \Omega-\mathrm{m}$ (Fig. 19.2). There is a good fit of the prediction of the $5.6 \Omega$-m uniform resistivity structure to the observed amplitude at $\leq 1,500 \mathrm{~m}$ separation, but large misfits are found at $>1,500 \mathrm{~m}$ separation. A twolayer model improves the fitting at $>1,500 \mathrm{~m}$ separation (Fig. 19.2); the resistivity of the upper layer down to $1,500 \mathrm{~m}$ depth is $5.6 \Omega-\mathrm{m}$, and that of the underlying halfspace is $0.1 \Omega-\mathrm{m}$. 


\subsubsection{Magnetic Field Anomalies and the Three-Dimensional Electrical Resistivity Structure}

Magnetic field anomalies for the optimal two-layer 1-D resistivity structure are shown in Figs. 19.3 and 19.4. On the $\mathrm{L} 1$ line, the $\mathrm{M} 3$ receiver exhibits a positive anomaly $(\leq 0.2 \log \mathrm{T} / \mathrm{A})$ at $1,500-2,200 \mathrm{~m}$ horizontal separation, and the M4 receiver shows a negative anomaly $(\geq-0.5 \log \mathrm{T} / \mathrm{A})$ at 1,500-2,500 $\mathrm{m}$ separation (Fig. 19.3). The M2 and M5 receivers exhibit small variations $(\leq 0.1 \log \mathrm{T} / \mathrm{A}$ in absolute value) (Fig. 19.3). The M1 receiver has different features on the four transmission lines of L2-5 (Fig. 19.4). Positive anomalies $(\leq 0.3 \log \mathrm{T} / \mathrm{A})$ are found at approximately $1,000 \mathrm{~m}$ and at 1,800-2,200 m separation on the L3 line, at $1,000-1,500 \mathrm{~m}$ separation on the L5 line, at 1,000-1,700 m separation on the L2 line, and at 1,400-1,800 m separation on the L4 line.

A resulting optimal 3-D resistivity structure is shown in Fig. 19.5. The magnitude and variation of the observed magnetic field anomalies (Figs. 19.3 and 19.4) provided a good initial guess for the 3-D resistivity structure, particularly in cross-areas of pairs of the transmitter and the receiver. A remarkable anomaly related to the Snail site is a conductor (C1) immediately below the site. Two resistive anomalies (R1 and R2) extending along the ridge axis sandwich the $\mathrm{C} 1$ conductive anomaly. Three other conductive anomalies (C2-4) to the north and west of the Snail site are required by the data. The reliability of the size and distribution of the deduced 3-D anomalies depends on the spatial coverage of transmitter-receiver pairs. The C1-3 and R1 anomalies are well constrained by the data due to good coverage. In contrast, the C4 and R2 anomalies, especially their lengths in the $y$-axis (across the ridge axis), are not strongly constrained.

Fitting of the prediction of the 3-D resistivity model to the observation in magnetic field anomaly is shown in Figs. 19.6 and 19.7. The optimal 3-D resistivity model explains the M2-M5 receiver data on the L1 line and the M1 receiver data on the $\mathrm{L} 3$ line. The misfit is large near the $\mathrm{M} 2$ receiver on the L4 line (Fig 19.7). A conductor near the M2 receiver would generate a positive magnetic field anomaly that could improve the fit, and we examined the possibility of such a conductor. However, the conductors tested generate positive magnetic field anomalies not only on the L4 line but also on the L3 line. Predicted positive magnetic field anomalies on the L3 line near the M2 receiver were inconsistent with the observed anomaly, and consequently, we do not believe that a significant conductor exists near the $\mathrm{M} 2$ receiver.

The resistivity values used for the 3-D conductive and resistive anomalies in this study are only one pair, 0.56 and $56 \Omega-\mathrm{m}$, and other resistivity values could explain the observation better. Even if there are better resistivity values, the optimal 3-D resistivity structure deduced in this study provides the general sense of the resistivity structure of
Fig. 19.3 Magnetic field anomalies observed at the M2-5 receivers for the $\mathrm{L} 1$ transmission line. The horizontal axis shows horizontal separations between the transmitter and the receiver along the L1 line. Triangles on the bottom of each panel represent receiver locations projected on the L1 line. The location of the M1 receiver, whose data are not plotted in the figure, is also shown by the gray triangle for reference. Colors are common for the magnetic field anomaly, the receiver name, and the receiver location

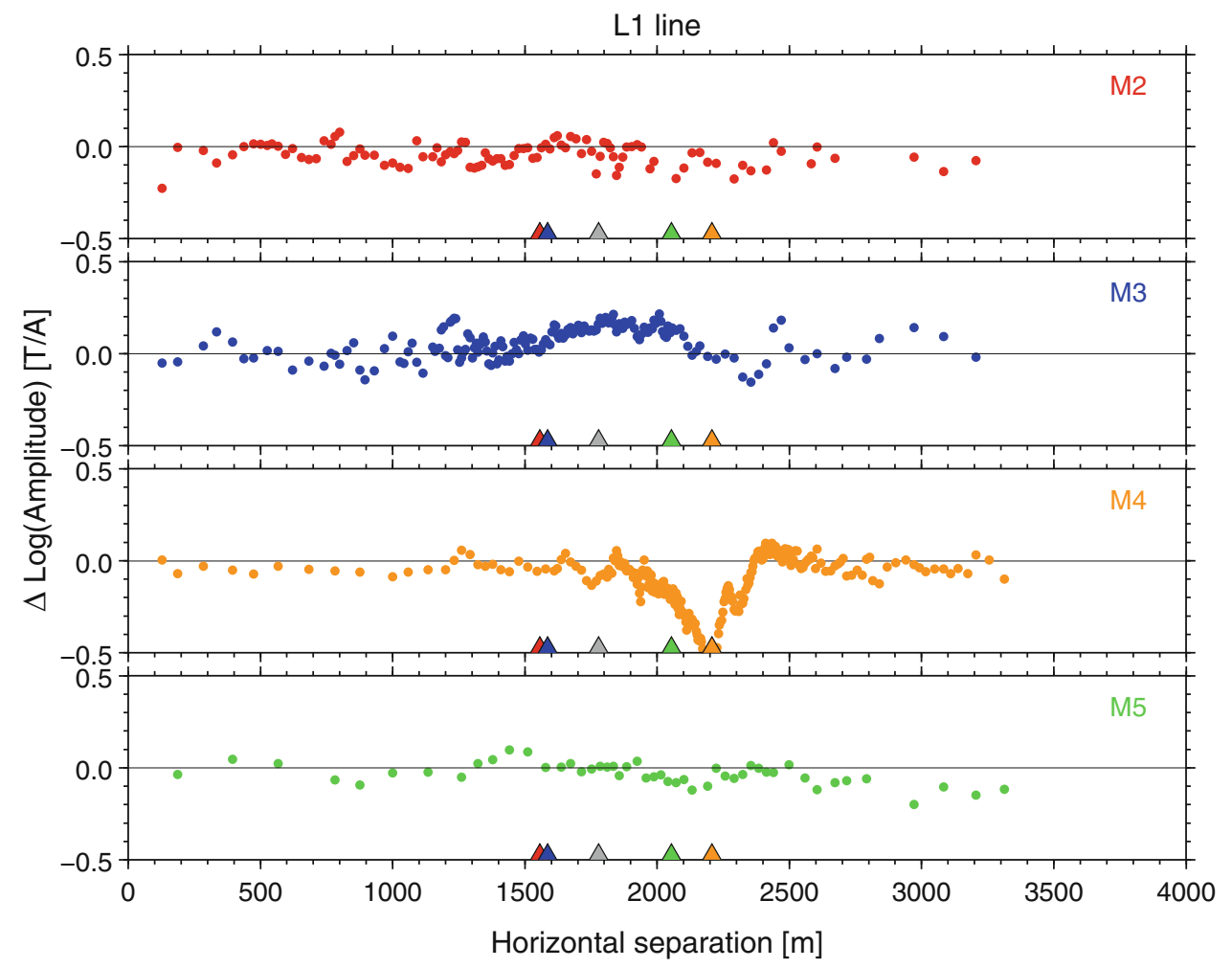


Fig. 19.4 Magnetic field anomalies observed at the M1 receiver from the $\mathrm{L} 2-5$ transmission lines. The horizontal axis shows horizontal separations between the transmitter and the receiver along each line. A gray triangle on the bottom of each panel denotes the location of the M1 receiver projected on each transmission line, and the other color triangles denote the locations of the other receivers (M2, red; M3, blue; M4, orange; M5, light green) for reference

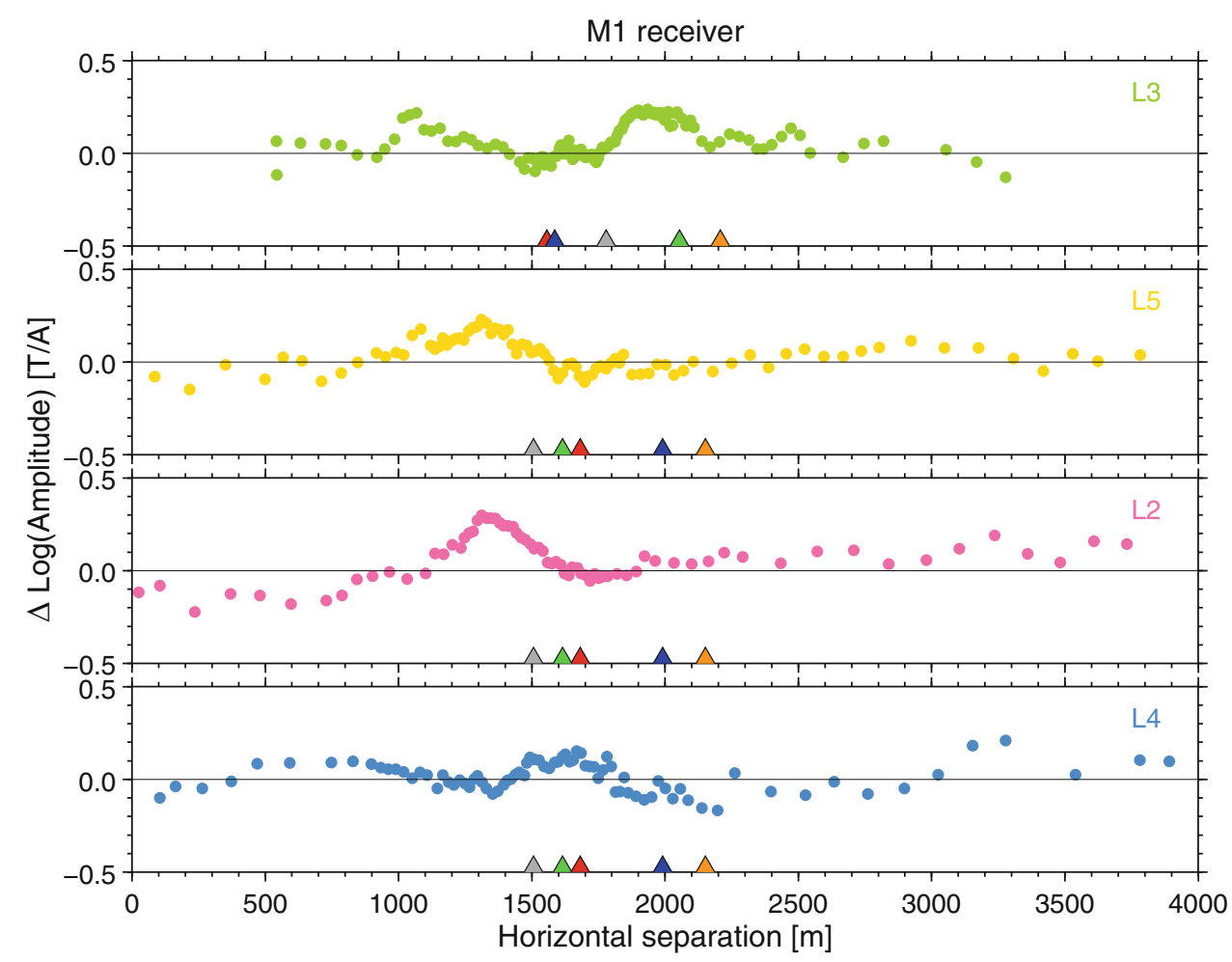

b

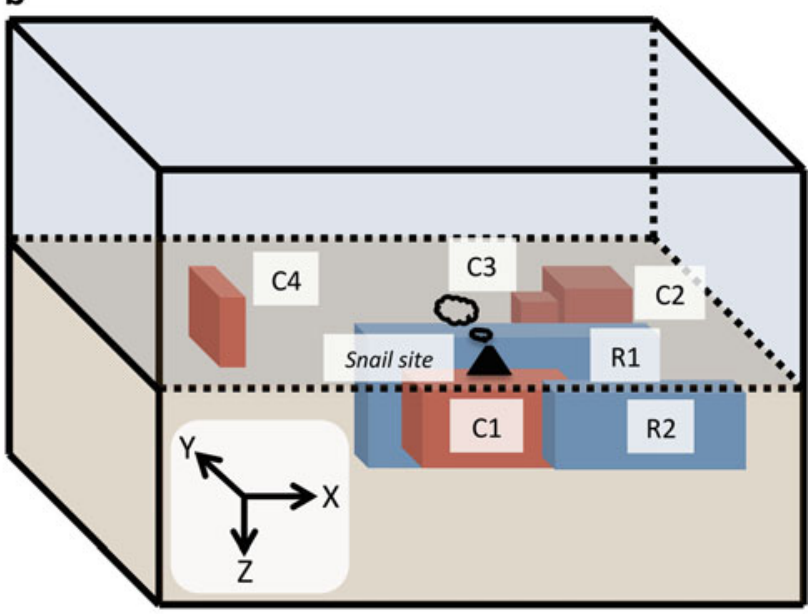

Dimensions of the bodies in $\mathrm{x}$ and $\mathrm{y}$ directions, and depths of the top and bottom in $z$ direction in meter ( $\left.x, y, z_{\text {top }}-\mathrm{z}_{\text {bottom }}\right)$.

C1: $350,250,50-400$

C2: $250,300,50-200$

C3: $150,200,50-200$

C4: $150,300,0-200$

R1: $600,200,0-500$

R2: 500, 200, 0-300

points (filled black circles) are also shown. The Snail site is located near the center of the map. (b) A schematic illustration of the optimal 3-D resistivity model viewed from the southeast. The dimensions of the conductive and resistive anomalies are shown below the illustration
Fig. 19.5 (a) A plan view map of the optimal 3-D resistivity model overlain on the seafloor topography. Red rectangles represent conductive anomalies $(0.56 \Omega-\mathrm{m})$, and blue rectangles represent resistive anomalies (56 $\Omega-\mathrm{m})$. Locations of the known hydrothermal sites (red circles), the receivers (colored triangles), and the transmission 
Fig. 19.6 Magnetic field anomalies observed and predicted from the optimal 3-D resistivity model (Fig. 19.5) for the M2-5 receivers on the $\mathrm{L} 1$ transmission line. Colored circles represent the predictions of the 3-D resistivity model, and gray circles behind the color circles represent the observation at each receiver. Triangles on the bottom of each panel represent locations of receivers projected on the transmission line. The location of the $\mathrm{M} 1$ receiver is also shown by gray triangles for reference
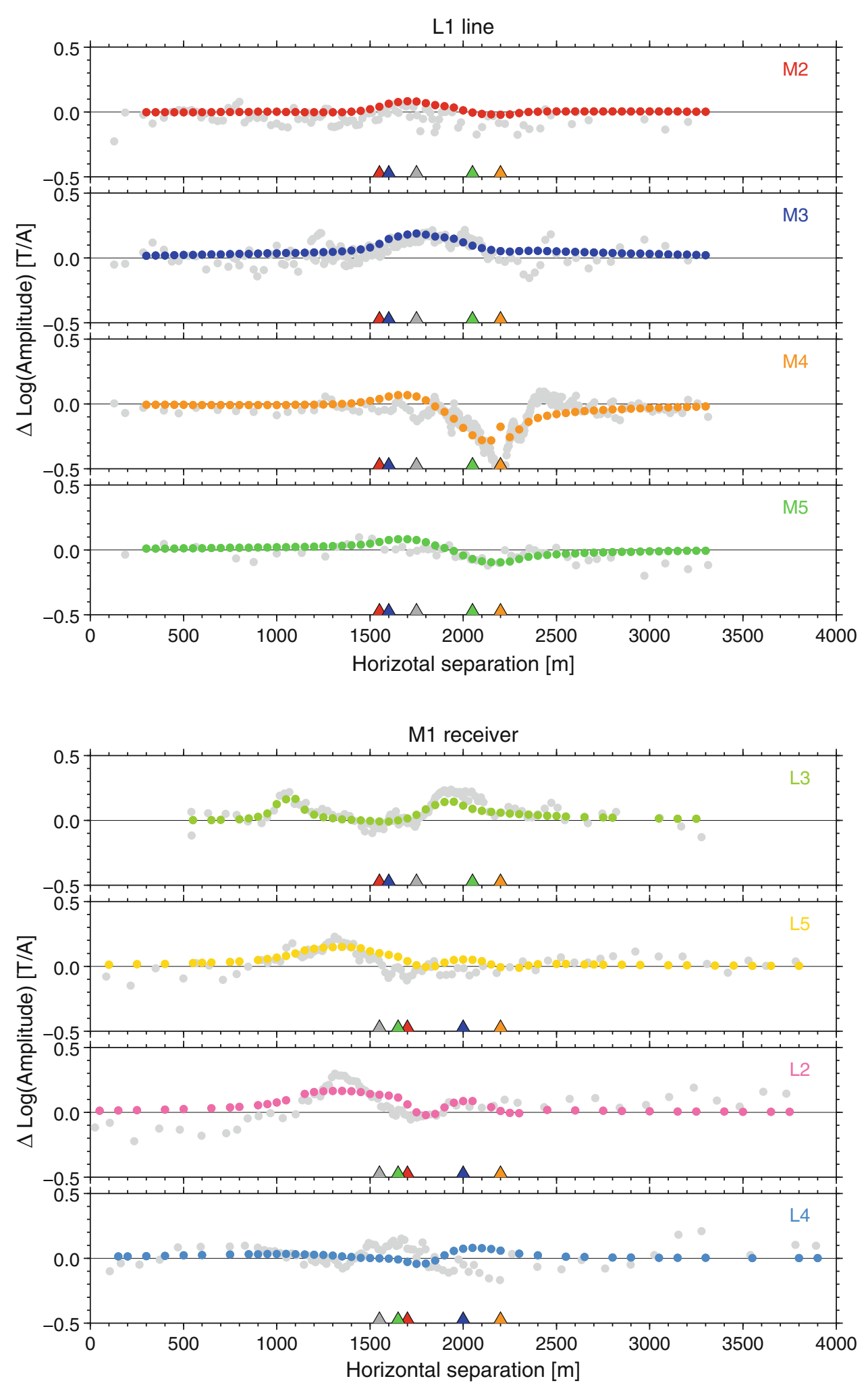

Fig. 19.7 Magnetic field anomalies observed and predicted from the optimal 3-D resistivity model (Fig. 19.5) for the M1 receiver on the $\mathrm{L} 2-5$ transmission line. Colored circles represent the predictions from the 3-D resistivity model, and gray circles represent the observation at the M1 receiver. Gray triangles on the bottom of each figure represent the location of the M1 receiver projected on each of the other receivers (M2, red; M3, blue; M4, orange; M5, light green) are also plotted for reference transmission line. The locations

the study area because the equivalency of conductance for different resistivities and different dimensions of a certain anomaly may be valid. As one example for the conductive body, a decrease in resistivity (i.e., the conductive anomaly becomes more conductive) can be compensated by a decrease in size.

\subsection{Discussion}

The optimal 1-D resistivity structure is the two-layered model (5.6 $\Omega$-m down to $1,500 \mathrm{~m}$ depth and $0.1 \Omega$-m further below). The optimal 3-D resistivity structure exhibits several 
lower and higher resistivity anomalies $(0.56$ and $56 \Omega$-m) than the basal 1-D resistivity structure at and around the Snail site (Fig. 19.5). The conductive anomaly of $\mathrm{C} 1$ is located immediately below the Snail site, and two resistive anomalies of R1 and R2 border the $\mathrm{C} 1$ anomaly and extend along the ridge axis. Three other conductive anomalies of C2-4 exist away from the Snail site.

Any resistivity value between 0.56 and $56 \Omega$-m in the 1-D and 3-D resistivity models is too low to represent the resistivity of basaltic upper oceanic crust without a conductive fluid at geothermal temperature (e.g., Drury and Hyndman 1979). The bulk resistivity of the oceanic crust, including the conductive fluid, has been reasonably explained by Archie's law (Archie 1942)

$$
\rho_{m} / \rho_{f}=\Phi^{-t}
$$

where $\rho_{m}$ is the bulk resistivity of a host (the crust), $\rho_{f}$ is the resistivity of conductive fluid in the host, $\Phi$ is the porosity of the host, and $t$ is a free exponent that has been proven and considered to depend on the interconnected form of the conductive fluid in the host (e.g., Sen et al. 1981; Mendelson and Cohen 1982). The resistivity of the conductive fluid in the oceanic crust changes with temperature, and an empirical relation between $\rho_{f}$ and fluid temperature, $T$, is introduced by

$$
T=0.34 / \rho_{f}^{2}+4.2 / \rho_{f}-16
$$

at $2-350{ }^{\circ} \mathrm{C}$ after the study of Nesbitt (1993).

Archie's law with the thermal dependence of the resistivity of fluid involves three variables (fluid temperature, porosity, free exponent: $T, \Phi, t$ ) and one observation (bulk resistivity: $\left.\rho_{m}\right)$. A possible range of fluid temperature is supposed to be $2-350{ }^{\circ} \mathrm{C}$. A porosity profile from Evans et al. (1998) is used for the porosity, which is a simplified profile of a DSDP ocean drilling at Hole 504B at the Costa Rica Rift of Becker (1989) (Fig. 19.8a). In the profile, the porosity is $17 \%$ in the top $200 \mathrm{~m}$ layer, decreases linearly to $2 \%$ at $200-800 \mathrm{~m}$ depth, and is a constant $2 \%$ down to $1,500 \mathrm{~m}$ depth (Fig. 19.8a). The porosity of the oceanic crust of the study area could be higher than this profile because less compression is expected for a younger oceanic crust (the seafloor age of the study area is almost $0 \mathrm{Ma}$, while that of Hole 504B is approximately $6 \mathrm{Ma}$ (Becker 1985)). We consider a hypothetical porosity profile for the newborn seafloor of the study area by assuming that $34 \pm 16 \%$

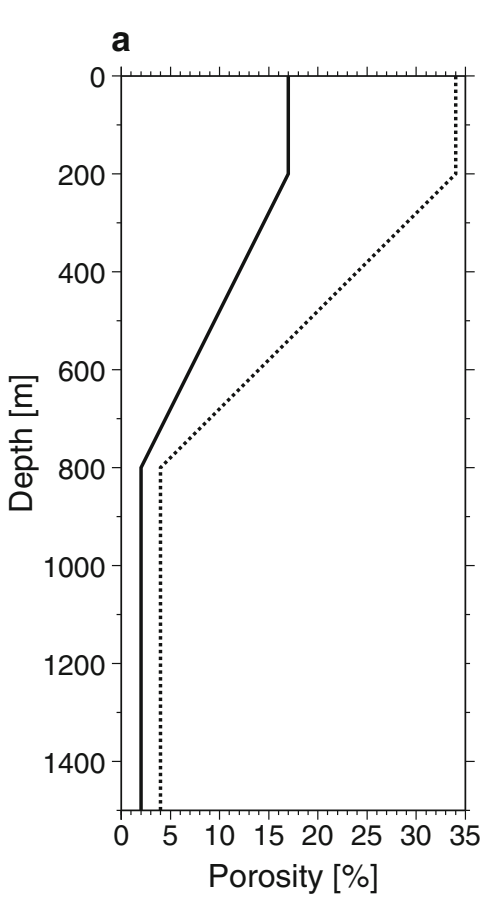

b

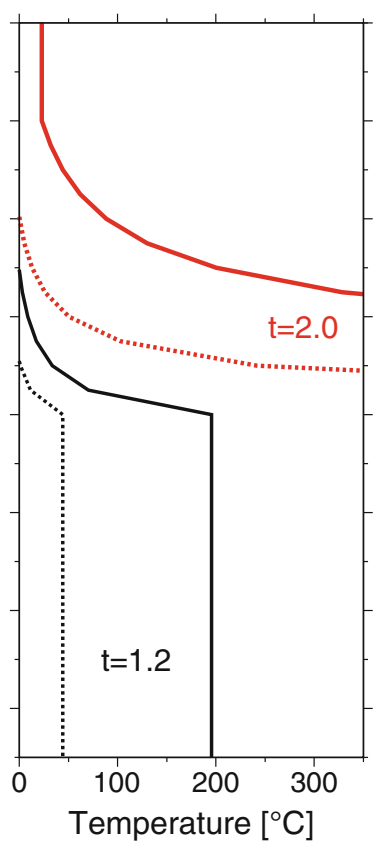

c

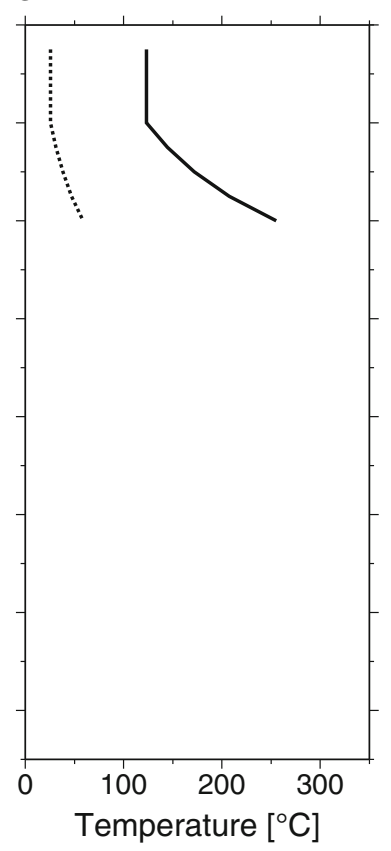

Fig. 19.8 (a) A porosity profile of the oceanic crust from Evans et al. (1998) (solid line) and a hypothetical profile of the doubled porosity (dotted line). (b) Profiles of fluid temperature within the crust for the resistivity of $5.6 \Omega-\mathrm{m}$ for the optimal 1-D resistivity structure. Solid lines represent estimations with the porosity profile from Evans et al. (1998), and dotted lines represent estimations with the hypothetical doubled porosity profile. Black and red colors show estimations with two exponents of 1.2 and 2.0 in Archie's law, respectively. (c) Profiles of fluid temperature within the crust for the conductive anomaly, $0.56 \Omega-\mathrm{m}$. A solid line represents an estimation with the porosity profile from Evans et al. (1998), and a dotted line represents an estimation with the hypothetical doubled porosity profile. The exponent in Archie's law is 1.2. The profiles are shown only at depths ranging from 50 to $400 \mathrm{~m}$, which is the depth range of the conductive anomaly 
porosity, which was estimated from outcrop rock samples at the northern Gorda Ridge (Pruis and Johnson 2002), is a plausible porosity for the uppermost crust. The hypothetical profile is just double of the porosity profile from Evans et al. (1998), and the highest porosity of the hypothetical profile is $34 \%$ in the uppermost layer (Fig 19.8a).

To determine a $t$ value in Archie's law, two representative exponents of 1.2 and 2.0 are examined, which were extensively used in prior studies (e.g., Becker 1985; Evans 1994). In general, a larger $t$ implies a less interconnected conductive fluid network through the rock (e.g., Evans 1994). With $\rho_{m}=5.6 \Omega-\mathrm{m}$ (the optimal 1-D resistivity structure) and the porosity profile from Evans et al. (1998), the fluid temperature for $t=1.2$ is negative, and that for $t=2.0$ is less than $200{ }^{\circ} \mathrm{C}$ down to $500 \mathrm{~m}$ depth (Fig. 19.8b). Below $500 \mathrm{~m}$ depth, the fluid temperature for $t=1.2$ is less than $200{ }^{\circ} \mathrm{C}$ and that for $t=2.0$ is over $350{ }^{\circ} \mathrm{C}$ (Fig. 19.8b). With $\rho_{m}=5.6 \Omega-\mathrm{m}$ and the hypothetical porosity profile, the fluid temperatures for $t=1.2$ and $t=2.0$ both decrease, but the temperature for $t=2.0$ results in over $350{ }^{\circ} \mathrm{C}$ below approximately $700 \mathrm{~m}$ depth (Fig. 19.8b). For the possible range of fluid temperatures $\left(2-350{ }^{\circ} \mathrm{C}\right), t=1.2$ yields more reasonable fluid temperatures for the optimal 1-D resistivity structure than $t=2.0$. We use $t=1.2$ in further discussions.

The fluid temperature at depths ranging from 800 to $1,500 \mathrm{~m}$ is estimated to be at $44-200{ }^{\circ} \mathrm{C}$ (Fig. 19.8b). This temperature is likely supported by the data from the magnetic field amplitude (Fig. 19.2). A prediction of the magnetic field amplitude from a model in which $2{ }^{\circ} \mathrm{C}$ seawater was forced to exist at depths of 800-1,500 $\mathrm{m}\left(\mathrm{T}=2{ }^{\circ} \mathrm{C}\right.$ line in Fig. 19.2) yields a different trend from the observation. The trend is especially different at $\geq 1,200 \mathrm{~m}$ horizontal separation, where the observed data are probably sensitive to the structure at depths of 800-1,500 $\mathrm{m}$ (Fig. 19.2). This result suggests that fluid estimated at $44-200{ }^{\circ} \mathrm{C}$ is not replaced by $2{ }^{\circ} \mathrm{C}$ seawater. Fluid at $44-200{ }^{\circ} \mathrm{C}$ and at depths of 800-1,500 m may represent a hydrothermal heating zone, one example of which was deduced at the East Pacific Rise (Tolstoy et al. 2008).

The resistivity of $0.1 \Omega$-m below $1,500 \mathrm{~m}$ depth in the optimal 1-D resistivity structure implies a magma mush under the spreading ridge, which is a heat source for the hydrothermal circulation at the Snail site. The resistivity of $0.1 \Omega-\mathrm{m}$ is proper for a basaltic silicic melt $(\leq 1 \Omega-\mathrm{m}$ at $\geq 1,200{ }^{\circ} \mathrm{C}$ ) (e.g., Tyburczy and Waff 1983). A low seismic velocity below $1,500 \mathrm{~m}$ depth on the ridge axis (Sato et al. Chap. 18) likely supports the presence of the heat source. Unfortunately, the conductive structure of $0.1 \Omega-\mathrm{m}$ is not reliable because the data for the long horizontal separation, which is sensitive to deeper structures, is sparse (Fig. 19.2).

The conductive anomaly of $0.56 \Omega-\mathrm{m}$ immediately below the Snail site (C1 in Fig. 19.5) is examined. The depth of the conductive anomaly is determined to be $50-400 \mathrm{~m}$, and the fluid temperature for the conductive anomaly is estimated to be $120-260{ }^{\circ} \mathrm{C}$ for the lower porosity (17-12\%) and $26-59{ }^{\circ} \mathrm{C}$ for the higher porosity (34-24\%) at these depths (Fig. 19.8c). These fluid temperatures suggest that there is hydrothermal fluid related to the Snail site activity, although the estimation of temperature changes with porosity.

The two resistive anomalies of $56 \Omega-\mathrm{m}$ near the Snail site (R1 and R2 in Fig. 19.5) are examined. Assuming $2{ }^{\circ} \mathrm{C}$ seawater, the upper bound of porosity for the resistive anomalies is inferred to be $1 \%$. This low porosity suggests that these areas would not involve a lot of fluid, potentially because this area is massive and less fractured. The regions of high resistivity could act as barriers for across-axis hydrothermal circulation, leading to preferential along-axis circulation, similar to the observation at the East Pacific Rise (Tolstoy et al. 2008).

The conductive anomalies away from the Snail site (C2-4 in Fig. 19.5) are unlikely to be related to the hydrothermal circulation at the Snail site because of their distance from the Snail vents. There is no evidence for active vents near these conductive anomalies. The conductive anomalies are located in areas dominated by normal faulting (Yoshikawa et al. 2012; Asada et al. Chap. 20). Faulting of the oceanic crust prompts a local increase in permeability (Becker et al. 1994) and may result in high porosity and the conductive anomalies. Weak crustal magnetizations near the conductive anomalies (Seama et al. Chap. 17) could suggest relic hydrothermal systems and low porosity (and low resistivity) due to the presence of past hydrothermal paths.

\subsection{Conclusion}

We carried out an MMR experiment at the Snail site on the ridge axis of the Southern Mariana Trough, and deduced basal 1-D and detailed 3-D resistivity models of the oceanic crust under the Snail site. The 1-D resistivity model suggests that high-temperature fluid at $44-200{ }^{\circ} \mathrm{C}$ exists at depths of $800-1,500 \mathrm{~m}$. The conductive structure below 1,500 $\mathrm{m}$ depth in the basal 1-D model implies a magma mush as a heat source for the hydrothermal circulation. The 3-D resistivity model contains a conductive anomaly immediately below the Snail site and two resistive anomalies adjacent to the conductive anomaly. The conductive anomaly immediately below the Snail site suggests the presence of hydrothermal fluid at $26-260{ }^{\circ} \mathrm{C}$ that is certainly related to the hydrothermal vent. The size and distribution of the conductive and the resistive anomalies at and around the Snail site give a constraint on the size of the hydrothermal circulation and imply that the circulation preferentially develops along the ridge axis rather than across the ridge axis. 
Acknowledgement We thank the captain, the crews, and the scientific members (PI, Toshitsugu Yamazaki) of the KR03-13 cruise of $R / V$ Kairei for their strong support to the MMR experiment. Participation of on-board and on-land scientists and marine technicians in the experiment is appreciated: Noriko Tada, Hisanori Iwamoto, Kazuya Kitada, Hitoshi Tanaka, Yutaka Matsuura, Yusuke Sato, Tamami Ueno, Tadanori Goto, and Masashi Shimoizumi. Noriko Tada and Shigenori Otsuka provided program codes for the data analysis, which they developed and improved. This study is partly supported by the scientific program of TAIGA (Trans-crustal Advection and In-situ reaction of Global sub-seafloor Aquifer) sponsored by the Ministry of Education, Culture, Sports, Science and Technology (MEXT) of Japan. Comments and English edit by the reviewers, Rob L. Evans and Yoshifumi Nogi, and editors, Jun-ichiro Ishibashi and Kyoko Okino, were very helpful to improve the manuscript. The GMT software (Wessel and Smith 1998) was used for creating figures. TM was supported by the NIPR project KP-7.

Open Access This chapter is distributed under the terms of the Creative Commons Attribution Noncommercial License, which permits any noncommercial use, distribution, and reproduction in any medium, provided the original author(s) and source are credited.

\section{References}

Archie GE (1942) The electrical resistivity log as an aid in determining some reservoir characteristics. J Petrol Technol 5:1-8

Becker K (1985) Large-scale electrical resistivity and bulk porosity of the oceanic crust, DSDP Hole 504B, Costa-Rica rift. Initial Rep Deep Sea Drill Proj 83:419-427

Becker K (1989) Measurements of the permeability of the sheeted dikes in Hole 504B. Proc Ocean Drill Program Sci Results 111:317-325

Becker K, Morin RH, Davis EE (1994) Permeabilities in the Middle Valley hydrothermal system measured with packer and flowmeter experiments. Proc Ocean Drill Program Sci Results 139:613-626

Becker NC, Fryer P, Moore GF (2010) Malaguana-Gadao Ridge: identification and implications of a magma chamber reflector in the southern Mariana Trough. Geochem Geophys Geosyst 11: Q04X13. doi:10.1029/2009GC002719

Drury MJ, Hyndman RD (1979) The electrical resistivity of oceanic basalts. J Geophys Res 84:4537-4545. doi:10.1029/ JB084iB09p04537

Edwards RN, Law LK, DeLaurier JM (1981) On measuring the electrical conductivity of the oceanic crust by a modified magnetometric resistivity method. J Geophys Res 86:11609-11615. doi:10.1029/ JB086iB12p11609

Evans RL (1994) Constraints on the large-scale porosity and permeability structure of young oceanic crust from velocity and resistivity data. Geophys J Int 119:869-879. doi:10.1111/j.1365-246X.1994.tb04023.x

Evans RL, Webb SC, Jegen M, Sananikone K (1998) Hydrothermal circulation at the Cleft-Vance overlapping spreading center: results of a magnetometric resistivity survey. J Geophys Res 103:12321-12338. doi:10.1029/98JB00599

Evans RL, Webb SC, Crawford W, Golden C, Key K, Lewis L, Miyano H, Roosen E, Doherty D, RIFT-UMC Team (2002) Crustal resistivity structure at $9^{\circ} 50^{\prime} \mathrm{N}$ on the East Pacific Rise: results of an electromagnetic survey. Geophys Res Lett 29(6):6-1-6-4. doi:10. 1029/2001GL014106

Fryer P (1996) Evolution of the Mariana convergent plate margin system. Rev Geophys 34(1):89-125. doi:10.1029/95RG03476

Hussong DM, Uyeda S (1982) Tectonic processes and the history of the Mariana arc: a synthesis of the results of Deep Sea Drilling Project Leg 60. Initial Rep Deep Sea Drill Proj 60:909-929

Ishibashi J, Yamanaka T, Kimura H, Toki T, Noguchi T (2006) Time series change of fluid geochemistry in decade scale: case studies for hydrothermal systems in back-arc basin, Japan Geoscience Union, Annual Meeting Program with Abstract, Japan Geoscience Union, Tokyo, J161-014

Kakegawa T, Utsumi M, Marumo K (2008) Geochemistry of sulfide chimneys and basement pillow lavas at the southern Mariana Trough $\left(12.55^{\circ} \mathrm{N}-12.58^{\circ} \mathrm{N}\right)$. Resource Geol 58(3):249-266. doi:10.1111/j.1751-3928.2008.00060.x

Kitada K, Seama N, Yamazaki T, Nogi Y, Suyehiro K (2006) Distinct regional differences in crustal thickness along the axis of the Mariana Trough, inferred from gravity anomalies. Geochem Geophys Geosyst 7(4), Q04011. doi:10.1029/2005GC001119

Martínez F, Fryer P, Becker N (2000) Geophysical characteristics of the southern Mariana Trough, $11^{\circ} 50^{\prime} \mathrm{N}-13^{\circ} 40^{\prime} \mathrm{N}$. J Geophys Res 105 (B7):16591-16607. doi:10.1029/2000JB900117

Mendelson KS, Cohen MH (1982) The effects of grain anisotropy on the electrical properties of sedimentary rocks. Geophysics 47(2):257-263. doi:10.1190/1.1441332

Nesbitt BE (1993) Electrical resistivities of crustal fluids. J Geophys Res 98(B3):4301-4310. doi:10.1029/92JB02576

Nobes DC, Law LK, Edwards RN (1986) The determination of resistivity and porosity of the sediment and fractured basalt layers near the Juan de Fuca Ridge. Geophys J R Astr Soc 86(2):289-317. doi:10.1111/j.1365-246X.1986.tb03830.x

Nobes DC, Law LK, Edwards RN (1992) Results of a sea-floor electromagnetic survey over a sedimented hydrothermal area on the Juan de Fuca Ridge. Geophys J Int 110(2):333-346. doi:10.1111/j.1365246X.1992.tb00878.X

Pruis MJ, Johnson HP (2002) Age dependent porosity of young upper oceanic crust: insights from seafloor gravity studies of recent volcanic eruptions. Geophys Res Lett 29(5):20-1-20-4. doi:10.1029/ 2001 GL013977.

Seama N, Tada N, Goto T, Shimoizumi M (2013) A continuously towed vertical bipole source for marine magnetometric resistivity surveying. Earth Planets Space 65:883-891. doi:10.5047/eps.2013. 03.007

Sen PN, Scala C, Cohen MH (1981) A self-similar model for sedimentary rocks with application to the dielectric constant of fused glass beads. Geophysics 46(5):781-795. doi:10.1190/1.1441215

Tada N, Seama N, Goto T, Kido M (2005) 1-D resistivity structures of the oceanic crust around the hydrothermal circulation system in the central Mariana Trough using Magnetometric Resistivity method. Earth Planets Space 57(7):673-677

Tada N, Kido M, Seama N (2011) Development of a 3-dimensional forward program for magnetometric resistivity method: application to Alice Springs field. Abstract for workshop on ocean mantle dynamics: from spreading center to subduction zone, Chiba, Japan

Tolstoy M, Waldhauser F, Bohnenstiehl DR, Weekly RT, Kim W-Y (2008) Seismic identification of along-axis hydrothermal flow on the East Pacific Rise. Nature 451:181-184. doi:10.1038/nature06424

Tyburczy JA, Waff HS (1983) Electrical conductivity of molten basalt and andesite to 25 kilobars pressure: geophysical significance and implications for charge transport and melt structure. J Geophys Res 88(B3):2413-2430. doi:10.1029/JB088iB03p02413

Urabe T, Ishibashi J, Maruyama A, Marumo K, Seama N, Utsumi M (2004), Discovery and drilling of on- and off-axis hydrothermal sites in backarc spreading center of southern Mariana Trough, western Pacific. Eos Trans AGU 85(47). Fall Meet. Suppl., Abstract V44A-03

Wessel P, Smith WHF (1998) New, improved version of the Generic Mapping Tools released. Eos Trans AGU 79:579

Wheat CG, Fryer P, Hulme SM, Becker NC, Curtis A, Moyer C (2003). Hydrothermal venting in the southern most portion of the Mariana backarc spreading center at 12.57 degrees N. Eos Trans AGU, 84 (46). Fall Meet. Suppl., Abstract T32A-0920

Yoshikawa S, Okino K, Asada M (2012) Geomorphological variations at hydrothermal sites in the southern Mariana Trough: relationship between hydrothermal activity and topographic characteristics. Mar Geol 303-306:172-182 